\title{
Effects of RTV Coating on the Discharge Characteristics of A Suspension Glass Insulator
}

\author{
Suat IIIhan (iD \\ Department of Electrical Engineering, İstanbul Technical University Faculty of Electrical and Electronic Engineering, İstanbul, Turkey
}

Cite this article as: Illhan S. Effects of RTV Coating on the Discharge Characteristics of A Suspension Glass Insulator. Electrica, 2019; 19(2): 173-181.

\begin{abstract}
The present study shows the effects of room temperature vulcanizing (RTV) silicone rubber high voltage insulator coatings on the discharge characteristics of a cap-and-pin type suspension glass insulator. The study covers both laboratory investigations and 3D electric field analysis, considering the coated and uncoated glass insulators. An ultraviolet corona camera is used to detect the location of the discharges, and a partial discharge test system is used to obtain the discharge patterns and pulse magnitudes. The experimental work is only conducted for $50 \mathrm{~Hz}$ power frequency voltage. In addition to the laboratory investigations, 3D electrostatic field analysis is performed to determine how the RTV coatings on the glass insulators affect the field distributions.
\end{abstract}

Keywords: RTV coating, Partial discharge, Electric field

\section{Corresponding Author: \\ Suat Illhan}

\section{E-mail:}

ilhansu@itu.edu.tr

Received: 24.04.2019

Accepted: 11.06.2019

(c) Copyright 2019 by Electrica Available online at

http://electrica.istanbul.edu.tr

DOI: 10.26650/electrica.2019.19024

Content of this journal is licensed under a Creative Commons Attribution-NonCommercial 4.0 International License.

\section{Introduction}

Pollution is a common problem especially for outdoor high voltage insulators, operated near industrial regions, as well as coastal areas. Pollution-related problems are frequently observed for the conventional porcelain and/or glass insulators due to their hydrophilic surface properties. Several solutions have been developed to eliminate or to at least minimize the pollution-related problems for conventional insulators. Using silicone rubber insulators and applying room temperature vulcanizing (RTV) silicone rubber high voltage insulator coating (HVIC) to the porcelain and glass insulators are the main solutions to improve the pollution performance of outdoor high voltage insulation systems [1-5].

RTV silicone rubber coatings have gained considerable interest to increase the pollution performance of conventional outdoor porcelain and glass insulators. The first field trial and the first largescale applications of RTV coatings were conducted in 1973 and 1987, respectively [1-5].

Owing to the hydrophobic surface feature, RTV coatings suppress the leakage current, and therefore the flashover due to the pollution, which is the most important property of the coatings [6]. Many studies have been conducted on the suppression ability of the RTV coatings on the development of the leakage current by using several accelerated weathering tests. Salt-fog tests and rotating wheel tests are the beneficial tests to characterize the RTV coating materials [7-10]. The available researches related to RTV coatings are mainly concentrated on the hydrophobicity, and therefore, the suppression ability of RTV coatings upon the leakage current developments along the insulators.

It is known that electrical discharges become an important design factor not only due to the losses but also due to the electromagnetic interferences, commonly known as radio interferences [11]. The basic motivation of the present study is that there is a limited research about the effects of RTV coatings on the discharge characteristics of suspension insulators. As indicated in reference [12], audible noise from the towers located in the vicinity of residential areas can be extremely annoying to residents especially in case of fog and/or dew weather conditions, and RTV coatings can reduce the noise level. 
In the present study, the effects of RTV silicone coatings on the discharge characteristics of cap-and-pin type suspension glass insulators are investigated by using laboratory tests, as well as 3D elec-

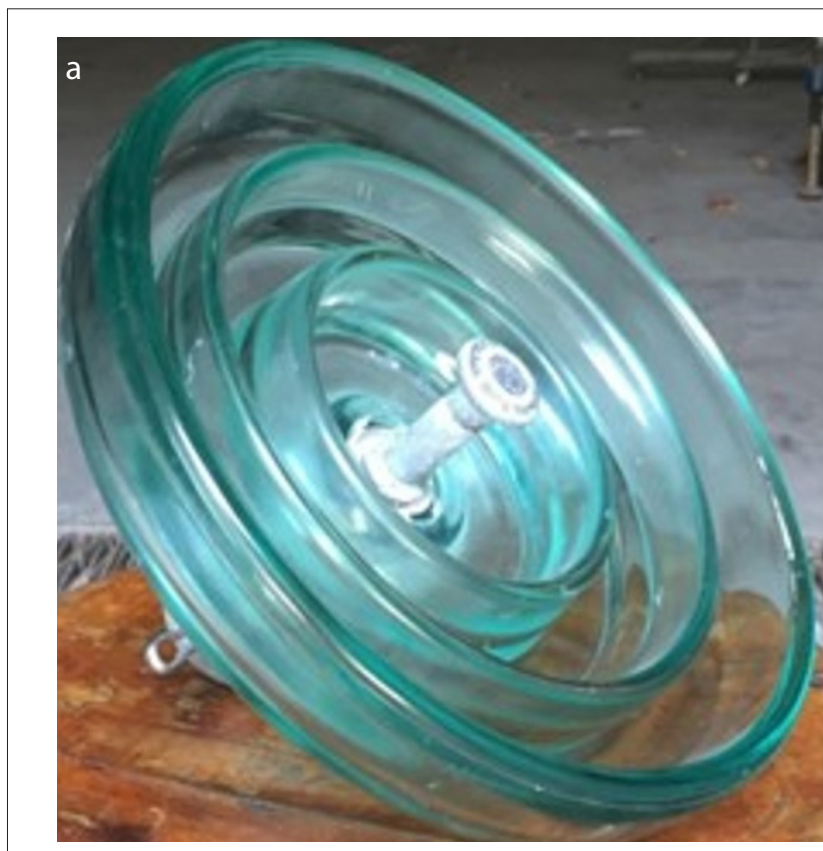

trostatic field analysis. An ultraviolet (UV) corona camera is used to detect both the location of the discharges and the number of pulses due to the discharges. Moreover, a partial discharge (PD) detector is

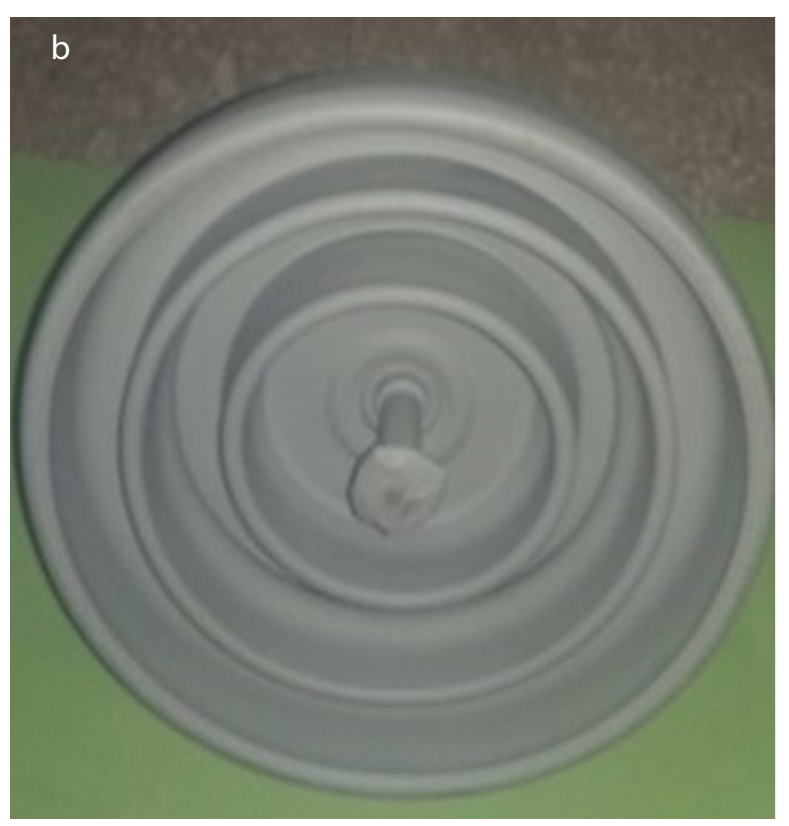

Figure 1. a, b. Uncoated glass insulator unit (a), RTV-coated glass insulator uni (b)
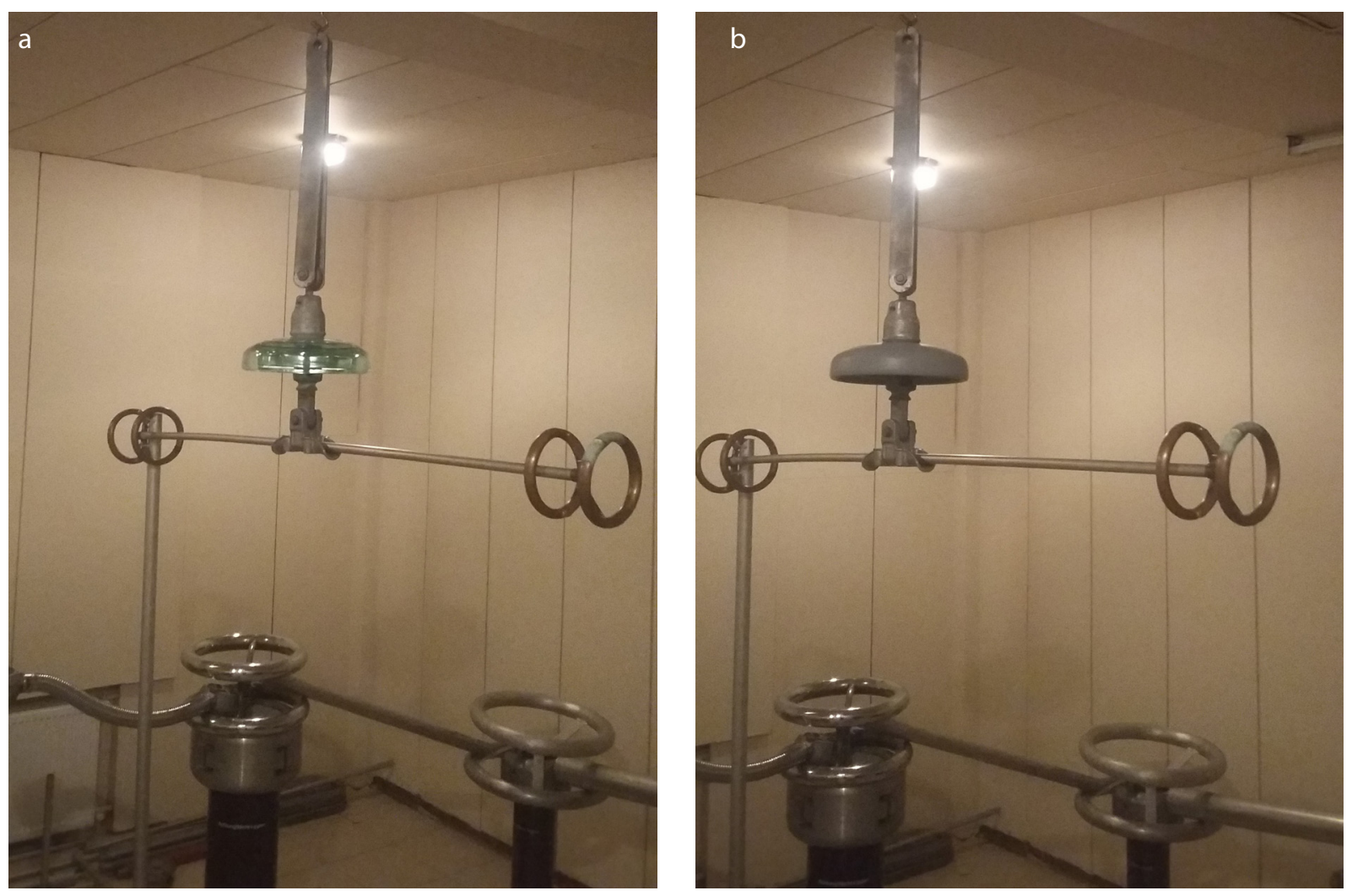

Figure 2. a, b. Laboratory test setup for (a) uncoated glass insulator unit and (b) RTV-coated glass insulator unit 
Table 1. Maximum PD magnitudes for the uncoated glass insulator units

\begin{tabular}{lcccc}
\hline & \multicolumn{4}{c}{ Maximum PD magnitudes (pC) } \\
\cline { 2 - 5 } Voltage $\left(\mathbf{k V}_{\mathbf{r m s}}\right)$ & 1st unit & 2nd unit & 3rd unit & Average \\
\hline 0.0 & 0.2 & 0.2 & 0.2 & 0.2 \\
\hline 2.5 & 0.7 & 0.5 & 0.3 & 0.5 \\
\hline 5.0 & 0.6 & 0.5 & 0.6 & 0.6 \\
\hline 7.5 & 0.6 & 0.5 & 0.8 & 0.6 \\
\hline 10.0 & 0.6 & 1.3 & 1.2 & 1.0 \\
\hline 12.5 & 1.8 & 16 & 40 & 19.3 \\
\hline 15.0 & 2.1 & 66 & 150 & 72.7 \\
\hline 17.5 & 110 & 290 & 320 & 240.0 \\
\hline 20.0 & 400 & 1100 & 770 & 756.7 \\
\hline 22.5 & 500 & 1500 & 1100 & 1033.3 \\
\hline 25.0 & 800 & 1800 & 1200 & 1266.7 \\
\hline 27.5 & 1200 & 1900 & 1500 & 1533.3 \\
\hline 30.0 & 1500 & 2100 & 1700 & 1766.7 \\
\hline 32.5 & 2000 & 2300 & 1900 & 2000.0 \\
\hline 35.0 & 2200 & 2500 & 2000 & 2233.3 \\
\hline 37.5 & 3000 & 100000 & 4000 & 35666.7 \\
\hline 40.0 & 200000 & 150000 & 175000 & 175000 \\
\hline & & & &
\end{tabular}

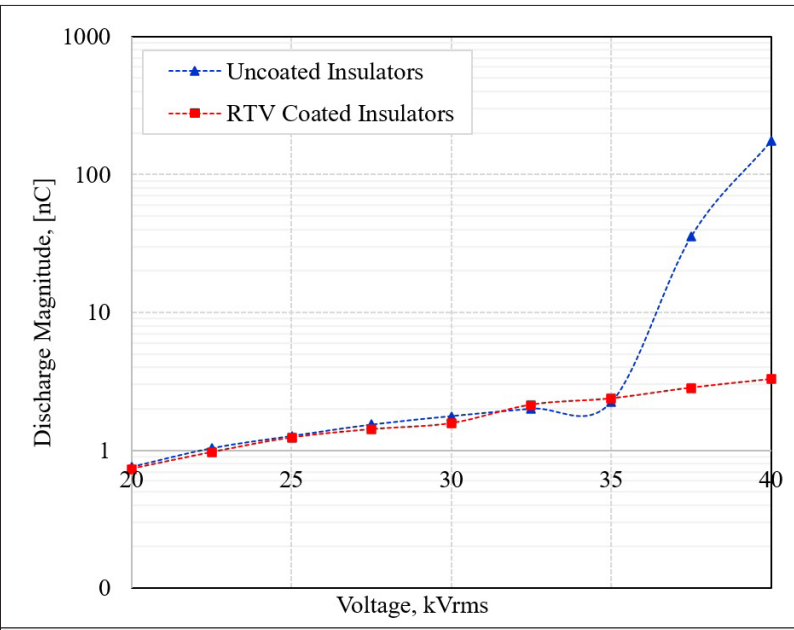

Figure 3. Maximum discharge magnitudes for RTV-coated and -uncoated glass insulator units

utilized to obtain the discharge magnitudes, as well as its patterns. In addition to the laboratory studies, the laboratory system is modeled in 3D geometry, and the field distributions corresponding to the coated and uncoated glass insulators are obtained to determine the effects of the RTV coatings on the field distributions.

\section{Experimental study}

Cap-and-pin type suspension glass insulators were used in the present study. The diameter of the insulator is $280 \mathrm{~mm}$, the
Table 2. Maximum PD magnitudes for the RTV-coated glass insulator units

\begin{tabular}{lcccc}
\hline & \multicolumn{4}{c}{ Maximum PD magnitudes (pC) } \\
\cline { 2 - 5 } Voltage $\left(\mathbf{k V}_{\mathbf{r m s}}\right)$ & 1st unit & 2nd unit & 3rd unit & Average \\
\hline 0.0 & 0.3 & 0.2 & 0.2 & 0.2 \\
\hline 2.5 & 0.3 & 0.3 & 0.3 & 0.3 \\
\hline 5.0 & 0.5 & 0.5 & 1.4 & 0.8 \\
\hline 7.5 & 1.6 & 0.6 & 1.5 & 1.2 \\
\hline 10.0 & 1.6 & 1.0 & 9.0 & 3.9 \\
\hline 12.5 & 1.6 & 1.2 & 11 & 4.6 \\
\hline 15.0 & 1.6 & 25 & 14 & 13.5 \\
\hline 17.5 & 200 & 180 & 330 & 236.7 \\
\hline 20.0 & 800 & 800 & 600 & 733.3 \\
\hline 22.5 & 1100 & 1000 & 800 & 966.7 \\
\hline 25.0 & 1600 & 1100 & 1000 & 1233.3 \\
\hline 27.5 & 1800 & 1250 & 1200 & 1416.7 \\
\hline 30.0 & 1800 & 1300 & 1600 & 1566.7 \\
\hline 32.5 & 3300 & 1400 & 1700 & 2133.3 \\
\hline 35.0 & 4000 & 1300 & 1800 & 2366.7 \\
\hline 37.5 & 4800 & 1600 & 2100 & 2833.3 \\
\hline 40.0 & 4800 & 2000 & 3000 & 3266.7 \\
\hline & & & & \\
\hline
\end{tabular}

spacing is $146 \mathrm{~mm}$, and the nominal creepage distance is 445 $\mathrm{mm}$. RTV-HVIC was applied to the glass insulators by using the spraying method. Three thin RTV coatings were applied consecutively in a 15-minute interval, and average wet thickness was obtained at approximately $0.5 \mathrm{~mm}$. Figure 1 shows the RTV-coated and -uncoated glass insulator units.

The experimental studies were performed at Istanbul Technical University, Fuat Kulunk High Voltage laboratory. A shielded test room with $6 m \times 6 m \times 3 m$ dimensions was used to implement the experiments. A noise-free testing transformer with $50 \mathrm{~Hz}$, $100 \mathrm{kV}$ maximum output voltage, and $20 \mathrm{kVA}$ rating was used for the tests. The background noise level of the test room was $<1 \mathrm{pC}$ up to $100 \mathrm{kV}$ testing voltage.

The insulator unit was suspended from the grounded ceiling through a $50 \mathrm{~cm}$ long metallic extension link. A $150 \mathrm{~cm}$ long smooth aluminum conductor was used to consider the line effect, and necessary hardware elements (e.g., suspension clamp) were used to connect the insulator unit to the line. The conductor was terminated by corona rings with $15 \mathrm{~cm}$ diameters at both ends to eliminate the terminal effects. The laboratory test setup of the insulator unit is illustrated in Figure 2.

The discharge characteristics of the glass insulator units were analyzed under AC voltage condition. Ambient conditions would be very effective on the discharge characteristics; therefore, the temperature and humidity of the test room were kept constant. The laboratory conditions were observed at a tem- 
perature of $26{ }^{\circ} \mathrm{C}$ and a relative humidity of $45 \%$. The experiments were repeated by using three identical units for both RTV-uncoated and -coated glass insulators to increase the reliability of the test results. Discharge levels of the insulators were measured by using a PD test system, with a fiber-optical measuring cable, and the discharge measurements were obtained through a quadrupole by using a $1007 \mathrm{pF}$ coupling capacitor. In addition to the PD test system, a daylight UV corona camera

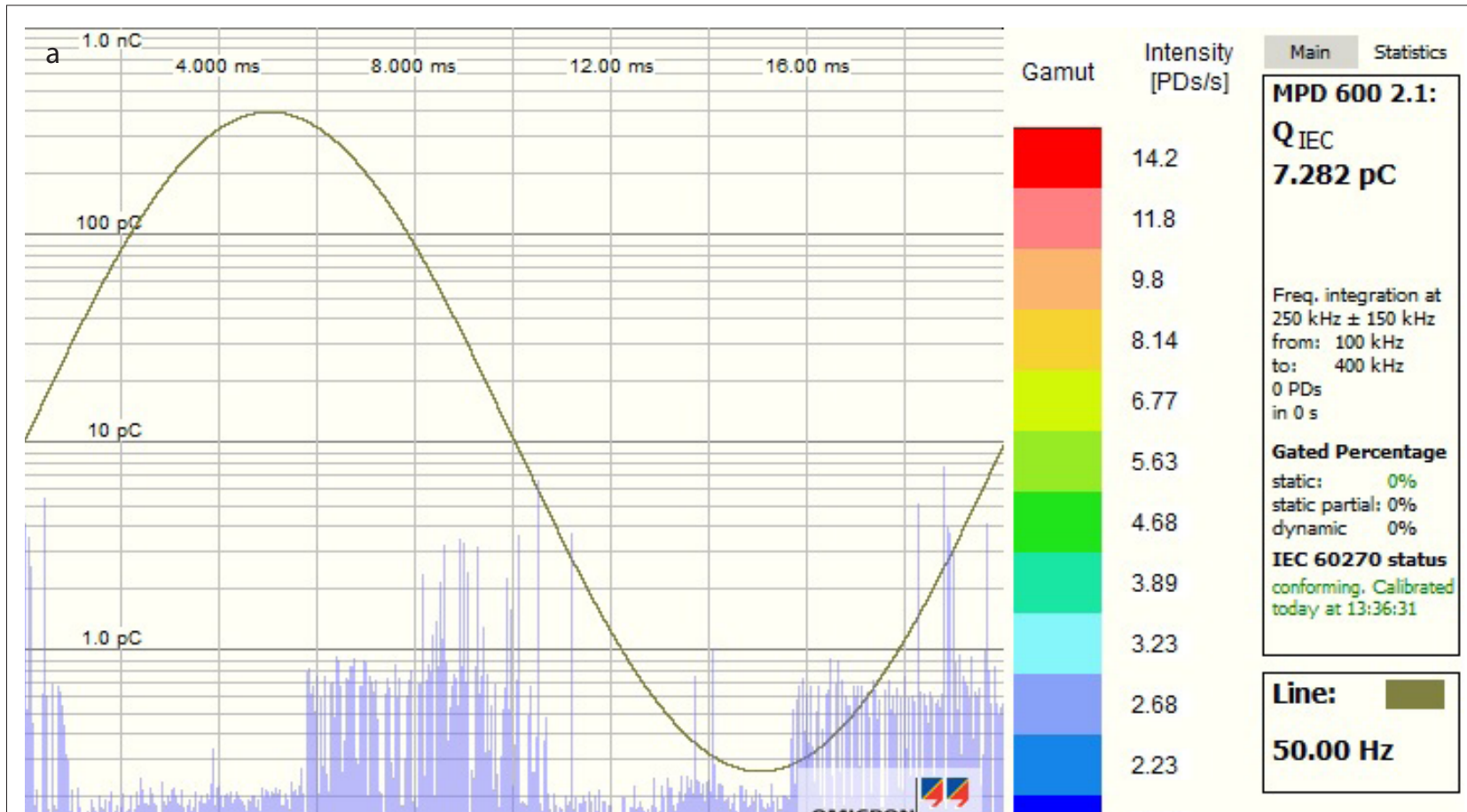

1.85

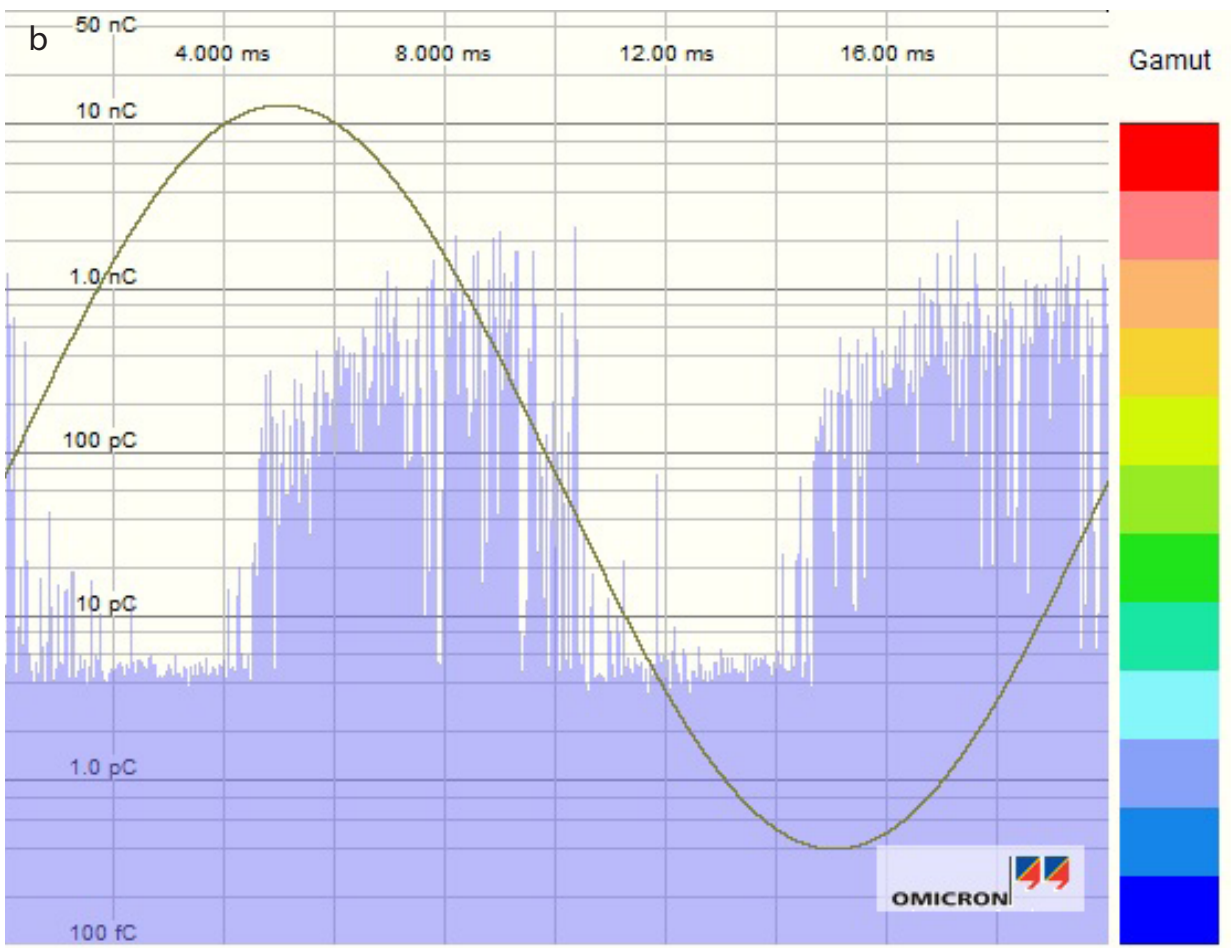

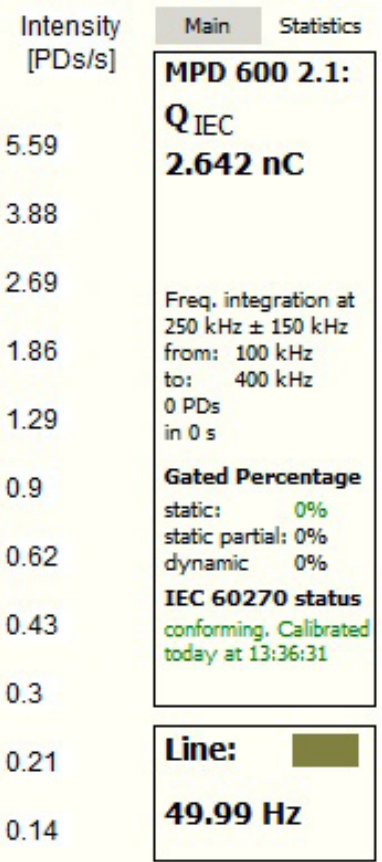

0.1

Figure 4. a, b. PD characteristics of the uncoated glass insulator unit for test voltage of (a) $10 \mathrm{kV}_{\mathrm{rms}}$ and (b) $30 \mathrm{kV}_{\mathrm{rm}}$ 


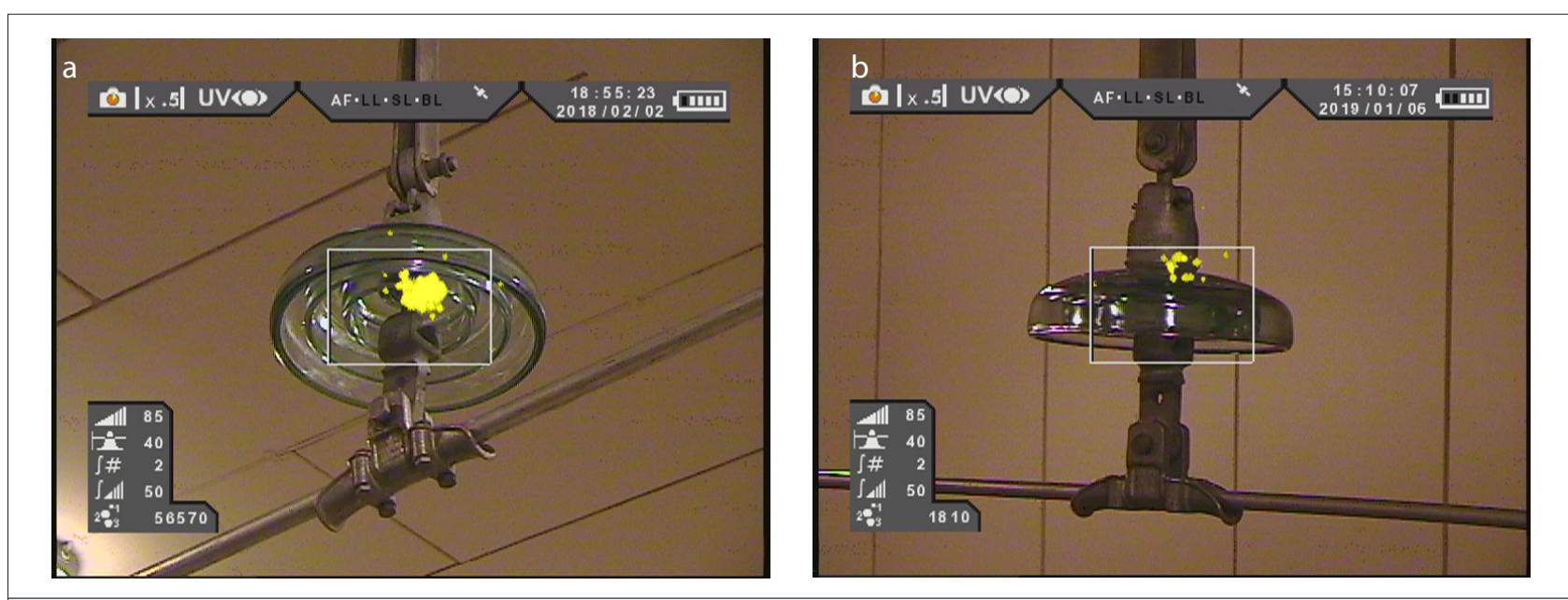

Figure 5. a, b. Discharges around the pin side of the uncoated unit (a). Discharges around the cap side of the uncoated unit (b)
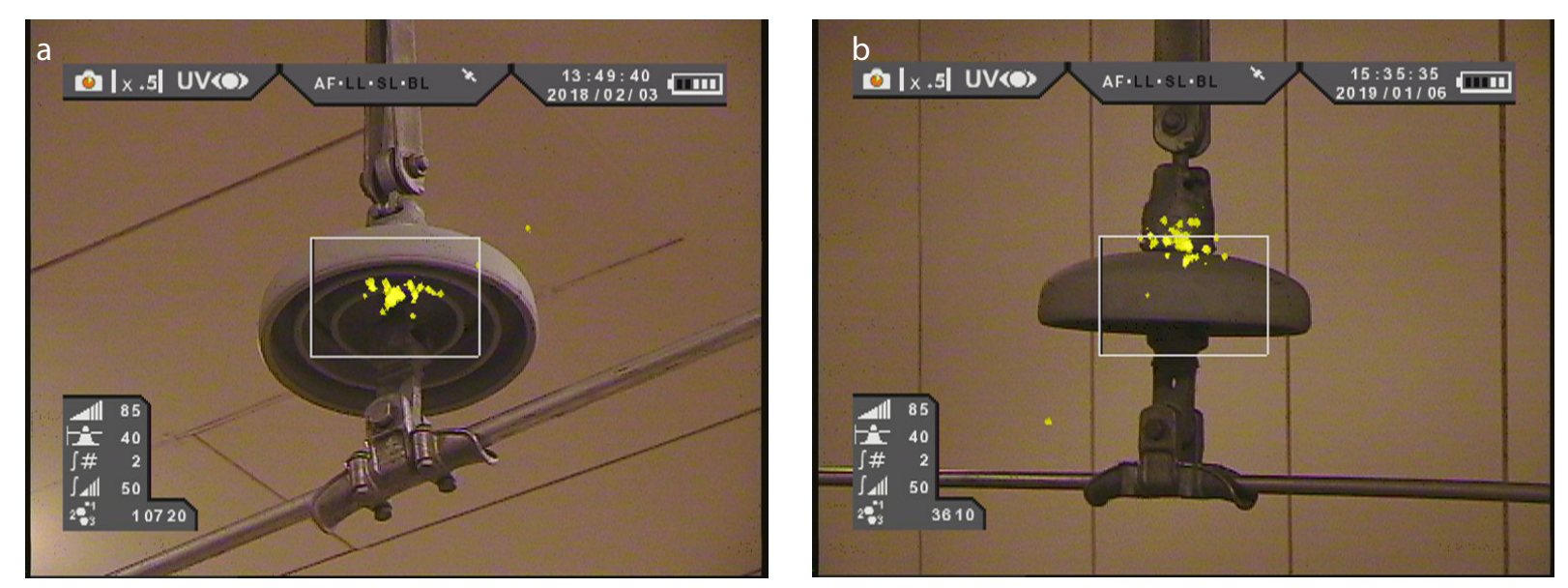

Figure 6. a, b. Discharges around the pin side of the RTV-coated unit (a). Discharges around the cap side of the RTV-coated unit (b)

was used to indicate the location of the corona discharges and to detect the corona pulse counts. The UV corona camera has $10^{-8} \mathrm{~W} / \mathrm{cm}^{2}$ minimum UV sensitivity.

The experimental studies were conducted up to $40 \mathrm{kV}_{\mathrm{rms}}, 50 \mathrm{~Hz}$ voltage. The voltage was increased from 0 to $40 \mathrm{kV}_{\text {rms }}$ voltage, and discharge characteristics were measured at voltages corresponding to $2.5,5.0,7.5,10 \ldots 40 \mathrm{kV}_{\text {rms }}$ voltage levels, with a total number of 17 measurement points. The PD test system was calibrated by using an external calibrator before starting the discharge measurements. For each voltage condition, at least $60 \mathrm{~s}$ of waiting time was considered. The averaged pulse magnitudes corresponding to the waiting time were recorded as pulse magnitudes for the relevant voltage condition. This procedure was applied for all the measurements. The measured discharge magnitudes for the uncoated and RTV silicone rubber-coated three glass insulator units are provided in Tables 1 and 2, respectively.

Figure 3 shows the discharge magnitude for coated and uncoated insulators for $20-40 \mathrm{kV}$ voltage range in a logarithmic scale. As shown in Figure 3, the surface PDs corresponding to the uncoated insulators are very severe, especially for voltage $>35 \mathrm{kV}$. Moreover, the discharge magnitudes for the uncoated insulators are relatively high as compared with the coated ones for test voltages up to $15 \mathrm{kV}$.

Surface discharge patterns for the uncoated glass insulator units are illustrated in Figure 4 for two different voltage levels. As shown in Figure 4, there is an increase in the maximum discharge magnitudes as the test voltage increases.

It is clear from Figure 4 that the discharge pulses appear on the first half cycle after the peak of the voltage. Similarly, the same discharge patterns occur for the second half cycle of the voltage.

The discharges captured by the daylight UV corona camera around the pin side and for the cap side for uncoated glass insulator unit are presented in Figure 5.

The discharges were also captured for the RTV-coated glass insulator units, and the recorded pictures are illustrated in Figure 6. 
It is clear from Figures 5 to 6 that for both coated and uncoated insulator elements, the pin side and cap side of the insulators are critical with respect to electrical discharges. In addition to the location of the corona discharges, the UV corona camera also measures the corona pulse counts, which indicate the discharge intensity. Corona pulse counts corresponding to the pin regions (Figures 5 and 6(a)) and the cap regions (Figures 5 and $6(b))$ were measured. The measurements showed that the discharges around the cap side of the insulators became visible at an earlier voltage than those of the pin side of the units. Moreover, the corona pulses on the UV corona camera screen would be visible when the PD magnitude was approximately 500-1000 pC. Note that the UV camera only detects the discharges on the visible part of the insulator, and due to this reason, pulse count results were not reported.

\section{Simulation study}

Several studies were conducted on the numerical analysis of electric fields along the silicone rubber insulators, and electric field and potential distributions were analyzed [13-15]. In the present study, similar electric field analysis was implemented for the RTV-coated glass insulators. The laboratory test setup as shown in Figure 2 was considered in the simulation studies. The glass insulator, a $0.5 \mathrm{~mm}$ thick RTV coating, the connections, and the smooth aluminum conductor were taken into account. A finite element method-based commercial software (Comsol Multiphysics) was used for the 3D simulation studies. Owing to the thin RTV silicone rubber coating on the glass insulator surface, a large number of meshing elements were required to discretize the 3D geometry. To reduce the meshing elements, and therefore the computational time, the symmetry condition of the test setup was considered. With the help of the plane symmetry condition, only $1 / 4$ portion of the geometry was modeled. Figure 7 shows the insulator element with coated surface and the simulation model considering the symmetry conditions.

The 3D model had approximately three million meshing elements. Relative dielectric permittivity of the glass shell, RTV silicone rubber coting, and cement region of the insulator were assigned as 4.2, 3.2, and 10.0, respectively. Electric potential and electric field distributions were obtained for both RTV-coated and -uncoated glass insulator units. Figure 8 shows the mesh distribution of the RTV-coated insulator, as well as the electric potential distribution.

Figure 9 illustrates the electric field distribution along the creepage path of the insulator unit for both RTV-uncoated and -coated insulator, considering a $1 \mathrm{kV}$ peak AC voltage. Maximum electric field strengths occur around the pin and cap regions, as shown in Figure 9, and the magnitude of the electric field around the cap region is the highest. It is clear that the RTV coating suppresses the maximum electric field strengths around both the pin region and the cap region.

As indicated in the experimental studies, corona discharges occurred around the cap and pin regions of the insulator unit, and the discharges around the cap region started earlier than those of the pin region. 3D electric field analysis results supported the

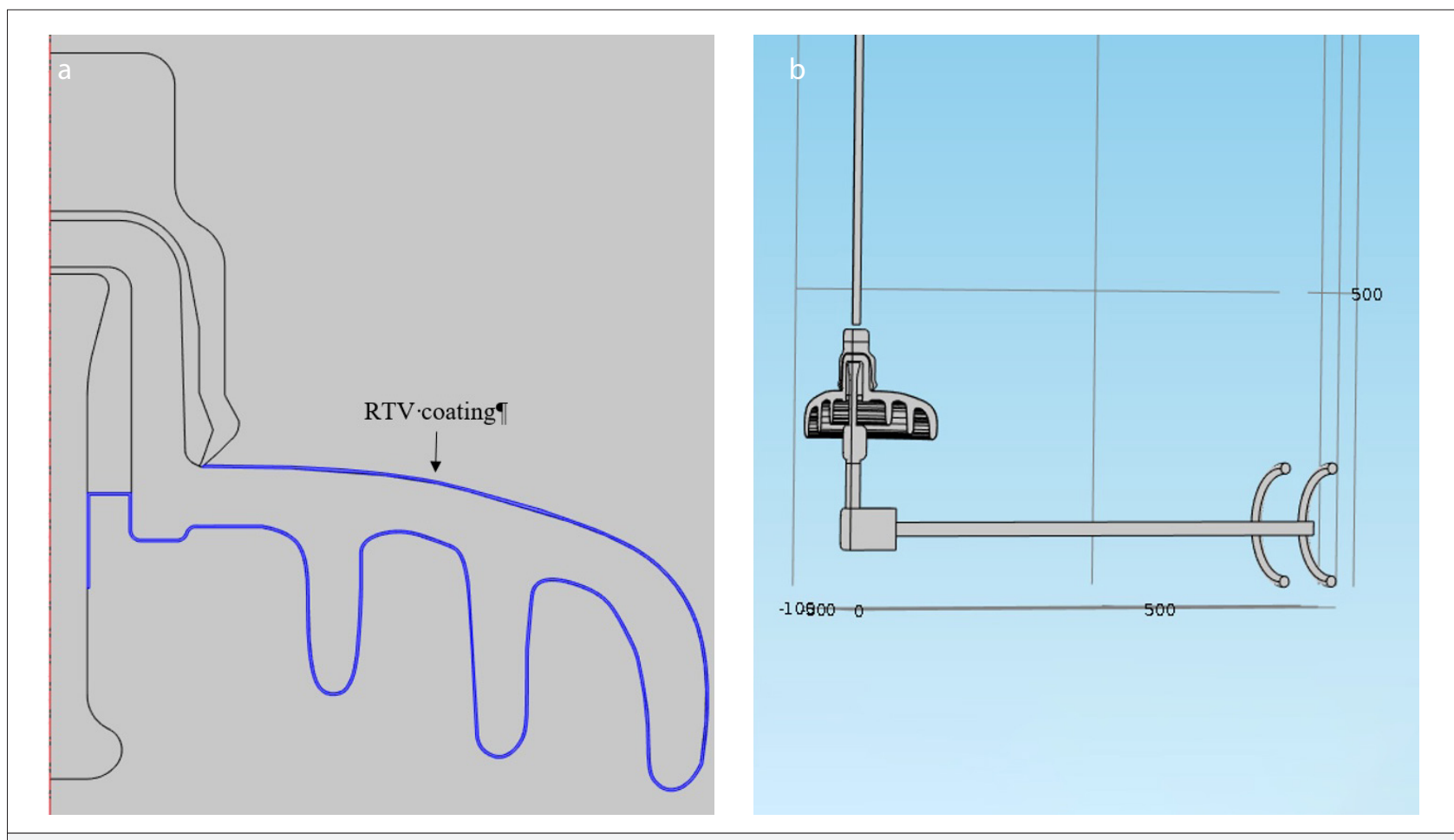

Figure 7. a, b. Model of the RTV-coated glass insulator (a). 3D laboratory model of the insulator unit (b) 


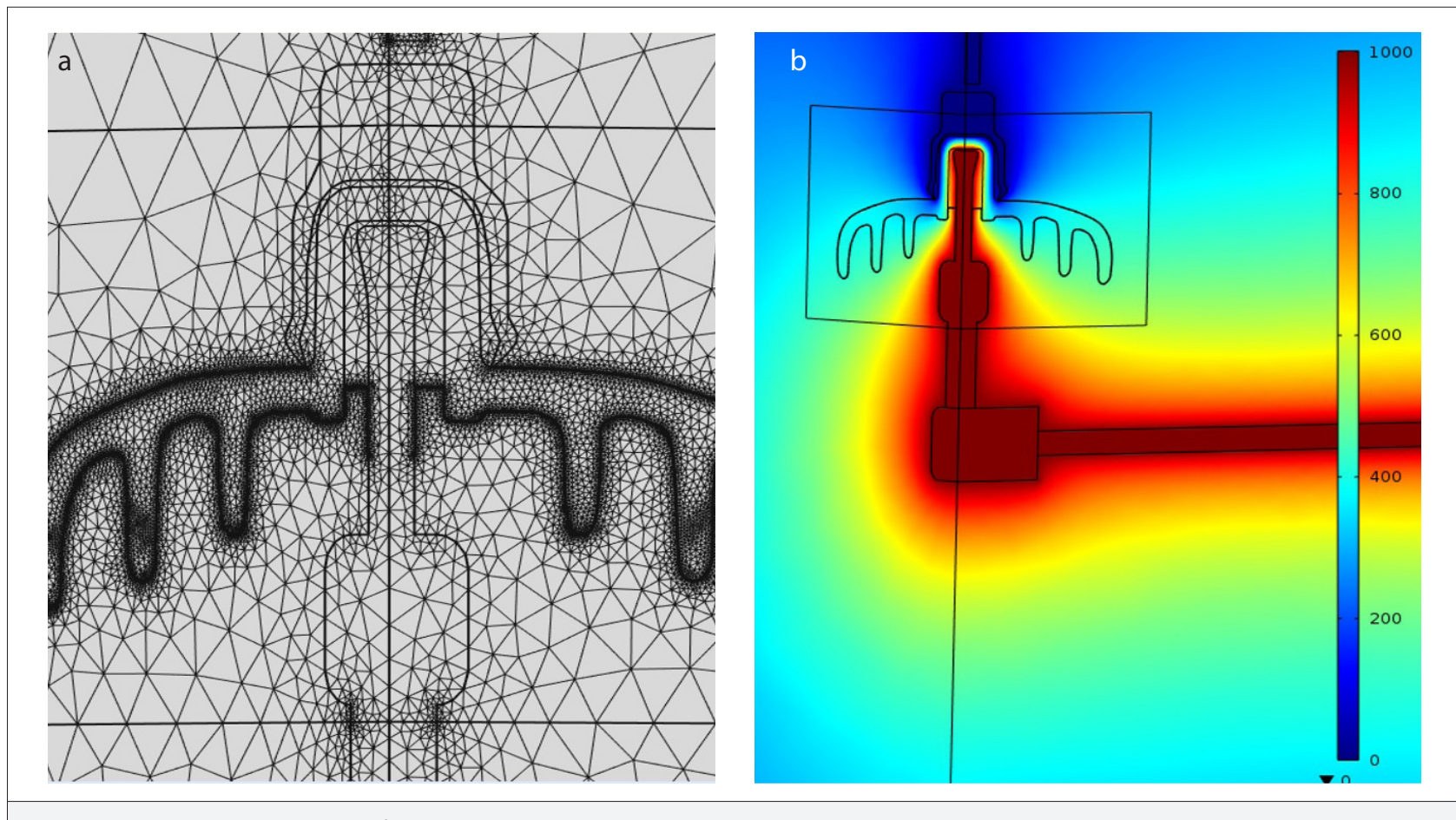

Figure 8. a, b. Mesh distribution of the insulator (a). 3D electric potential distribution around the insulator (b)

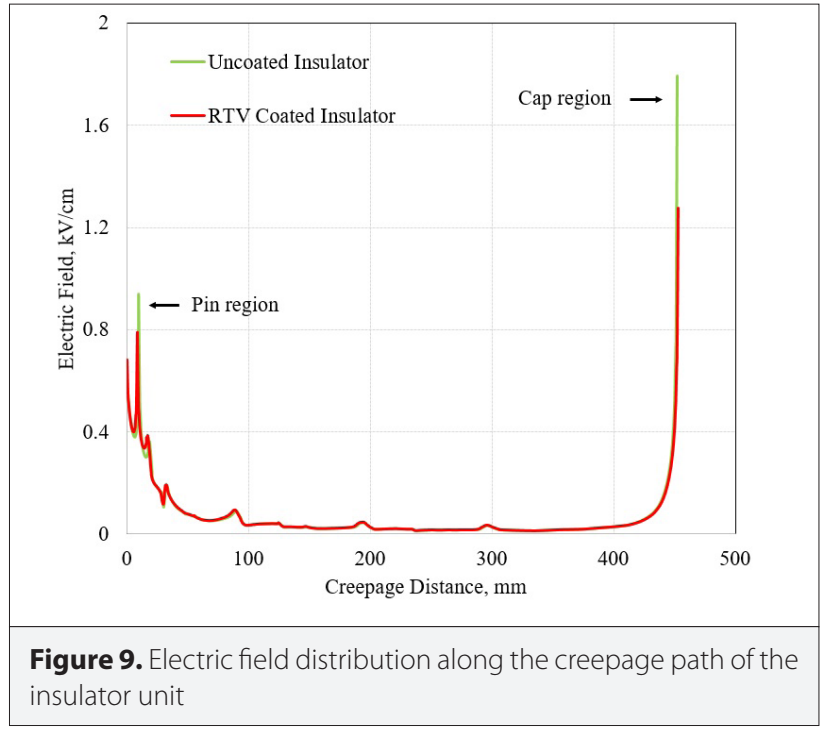

experimental results. The cap region and pin region were found to be the critical ones with respect to high electric field strengths. Moreover, the magnitude of the field strengths around the cap region is the highest, which indicates that the discharges around the cap region would start at an earlier voltage.

The experimental results showed that the magnitude of the surface PDs for the uncoated insulator is greater than that for the RTV silicone-coated insulator case, especially for voltage $>35 \mathrm{kV}$. Reduction in the maximum electric field strengths on the critical regions due to the RTV coating would be the reason for this condition.

\section{Conclusion}

The effects of the RTV silicone rubber coating on the discharge characteristics of a cap-and-pin type suspension glass insulator units are presented. Both the experimental and 3D simulation studies are conducted. The following summarize the research results:

- UV corona camera measurements indicated that the discharges occurred around the pin region and cap region of the insulator for both RTV-uncoated and -coated conditions. The discharges around the cap region started earlier than those of the pin region.

- In the case of the RTV silicone rubber coating condition, the magnitude of the surface discharge would be less as compared with the uncoated condition, especially for test voltages $>35 \mathrm{kV}$.

- The patterns of the surface discharges for the RTV-uncoated and -coated conditions showed similar behaviors.

- 3D electric field analysis showed that maximum electric field strengths occurred around the cap and the pin regions of the insulator, and the highest electric field strengths were obtained around the cap region. These results were also verified by the experimental measurements.

- The application of the RTV coatings on the insulator unit reduced the maximum electric field strengths on the cap and the pin regions of the insulator. 
Peer-review: Externally peer-reviewed.

Conflict of Interest: The author have no conflicts of interest to declare.

Financial Disclosure: This work was supported by Istanbul Technical University (BAP-41229).

\section{References}

1. E. A. Cherney, A. El-Hag, S. Li, R. S. Gorur, L. Meyer, I. Ramirez, M. Marzinotto, J. George, "RTV silicone rubber pre-coated ceramic insulators for transmission lines", Dielectrics and Electrical Insulation, IEEE Transactions on, vol. 20, no.1, pp.237-244, (2013). [CrossRef]

2. E. A. Cherney, M. Marzinotto, R. Gorur, I. Ramirez, S. Li, A. El-Hag, A. Tzimas, "End-of-life and replacement strategies for RTV silicone rubber coatings," Dielectrics and Electrical Insulation, IEEE Transactions on, vol.21, no.1, pp.253-261, (2014). [CrossRef]

3. J. Hall, T. Orbeck, "Evaluation of a New Protective Coating for Porcelain Insulators", IEEE Transaction on Power Apparatus and Systems", vol. PAS-101, No. 12, pp. 4689-4696, (1982). [CrossRef]

4. R. Carberry, H. M. Schneider, "Evaluation of RTV Coating for Station Insulators Subjected to Coastal Contamination", IEEE Transaction on Power Delivery, Vo. 4, No. 1, pp.577-585, (1989). [CrossRef]

5. A. E. Vlastos, E. Sherif, "Expeerience From Insulators With RTV Silicone Rubber Sheds and Shed Coatings", IEEE Transaction on Power Delivery, Vol. 5, pp.2030-2038, (1990). [CrossRef]

6. E. A. Cherney, "RTV silicone-a high tech solution for a dirty insulator problem," Electrical Insulation Magazine, IEEE , vol.11, no.6, pp.8-14, (1995). [CrossRef]

7. K. Seog-Hyeon, R. Hackam, "Effects of saline-water flow rate and air speed on leakage current in RTV coatings," IEEE Transactions on Power Delivery, vol.10, no.4, pp.1956-1964, (1995). [CrossRef]
8. R. S. Gorur, E. A. Cherney, R. Hackam, "A Comparative Study of Polymer Insulating Materials Under Salt-Fog Conditions," Electrical Insulation, IEEE Transactions on, vol. El-21, no.2, pp.175-182, (1986). [CrossRef]

9. R. S. Gorur, L. J. Johnson, H. C. Hervig, "Contamination performance of silicone rubber cable terminations," Power Delivery, IEEE Transactions on, vol.6, no.4, pp.1366-1373, (1991). [CrossRef]

10. A. Kohli, W. Zhu, S. A. Akbar, S. A. Sebo, J. D. Sakich, T. Zhao, "Characterization of polymeric housing materials of non-ceramic insulators after aging tests," Electrical Insulation, 1998. Conference Record of the 1998 IEEE International Symposium on, vol.2, no., pp.343-346 vol.2, (1998).

11. S. Ilhan, A. Ozdemir, "380 kV corona ring optimization for AC voltages," in IEEE Transactions on Dielectrics and Electrical Insulation, vol. 18, no. 2, pp. 408-417, (2011). [CrossRef]

12. M. Marzinotto, E. A. Cherney, G. Mazzanti, G. "RTV pre-coated cap-and-pin toughened glass insulators - a wide experience in the Italian overhead transmission system,"2015 IEEE Conference on Electrical Insulation and Dielectric Phenomena (CEIDP), Ann Arbor, MI, 2015, pp. 150-153.doi: 10.1109/CEIDP.2015.7351986, (2015). [CrossRef]

13. T. Zhao, M. G. Comber, "Calculation of electric field and potential distribution along non-ceramic insulators considering the effects of conductors and transmission towers", IEEE Trans. Power Deliv., 15, 313-318, (2000). [CrossRef]

14. A. J. Phillips, J. Kuffel, A. Baker, J. Burnham, A. Carreira, E. Cherney, W. Chisholm, M. Farzaneh, R. Gemignani, A. Gillespie, T. Grisham, R. Hill, T. Saha, B. Vancia, J. Yu, "Electric fields on AC composite transmission line insulators", IEEE Trans Power Deliv, 23 (2), 823-830, (2008). [CrossRef]

15. W. Que, S. A. Sebo, R. J. Hill, "Practical cases of electric field distribution along dry and clean non-ceramic insulators of high-voltages power lines", IEEE Trans Power Deliv 22 (2), 1070-1078, (2007). [CrossRef] 


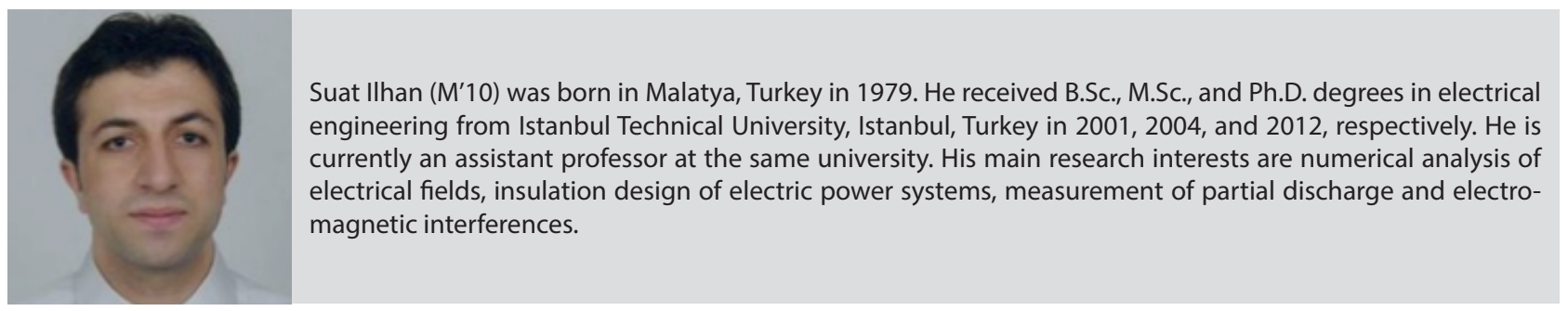

